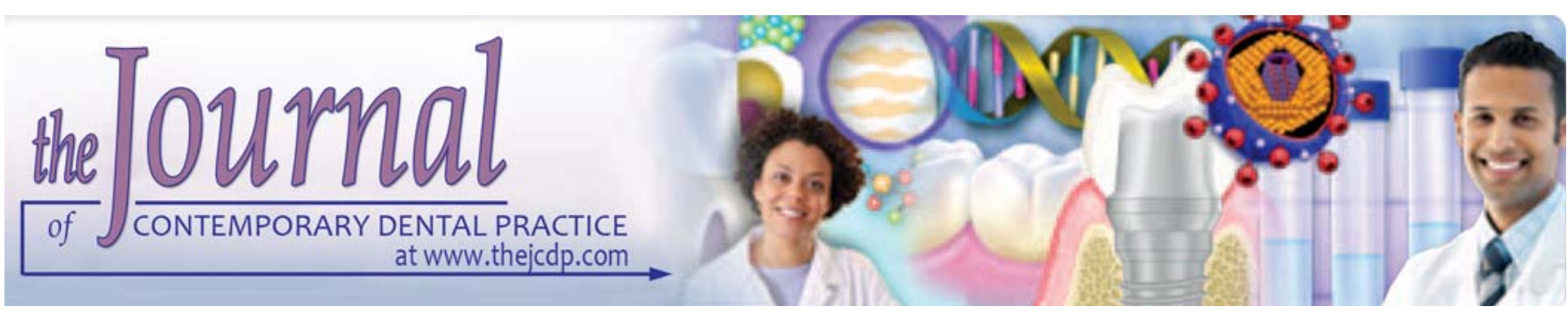

\title{
Endodontic Treatment of a Maxillary Central Incisor with Two Roots
}

Amir Maghsoudlou, Hamid Jafarzadeh, Maryam Forghani

\section{ABSTRACT}

Aim: This clinical report presents a rare case of maxillary central incisor with two separate roots.

Background: Unusual morphology of the roots and root canals may exist in any tooth. Recognition of the dental anatomy and its variations is necessary for successful endodontic therapy. It is well known that maxillary incisors are usually single-rooted teeth.

Case report: The root canals were instrumented with conventional hand files and Gates Glidden and obturated by using the lateral technique. Recall radiograph after 1 year shows the healing process of the preoperative apical periodontitis.

Conclusion and clinical significance: Clinicians should be aware of unexpected root canal morphology when performing root canal therapy. The present case demonstrated the importance of accurate preoperative radiograph and adequate access preparation.

Keywords: Maxillary central incisor, Endodontic treatment, Root canal.

How to cite this article: Maghsoudlou A, Jafarzadeh $\mathrm{H}$, Forghani M. Endodontic Treatment of a Maxillary Central Incisor with Two Roots. J Contemp Dent Pract 2013;14(2):345-347.

\section{Source of support: Nil}

Conflict of interest: None declared

\section{INTRODUCTION}

Successful endodontic treatment depends on the cleaning, shaping and obturation of the entire root canal system. Knowledge of the dental anatomy and root canal morphology is one of the main factors affecting the success of endodontic treatment. ${ }^{1}$ Practitioners must consider the possible anatomical variations in the number of the roots and root canals because failure to discover the additional canals often results in a lack of resolution of the associated inflammatory process. Careful interpretation of preoperative radiographs is very important for diagnosing the teeth with unusual root anatomy.
Many anatomical studies have reported that maxillary central incisor is a single-rooted tooth. ${ }^{2,3}$ The present case reports the features and endodontic therapy of a maxillary central incisor with two roots and two root canals, demonstrated by radiography and computed tomography (CT) examination.

\section{CASE REPORT}

A 22-year-old male patient was referred to Department of Endodontics of Mashhad Faculty of Dentistry with a history of a dull pain in the upper anterior teeth. He had no problem in his medical history. Dental history revealed that the patient had experienced traumatic injury to the upper left central incisor few years ago. Clinical examination showed discoloration of the crown and a pit and caries on the buccal surface of the tooth (Fig. 1). The tooth did not respond to thermal and electrical pulp tests; however, the adjacent teeth responded to these tests within normal limits. Tooth \# 9 was sensitive to percussion. The periodontal probing and

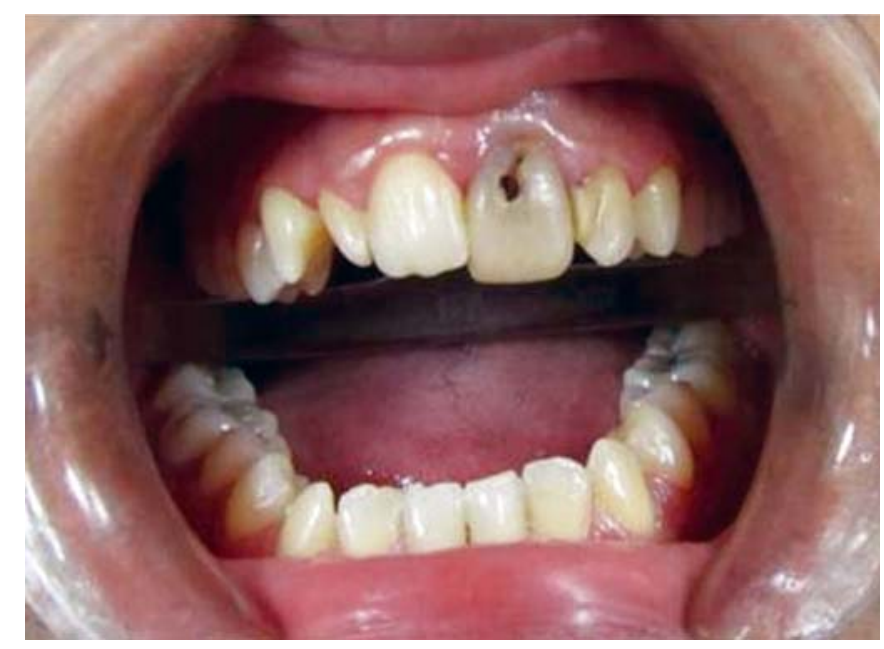

Fig. 1: Left maxillary central incisor with crown discoloration and decay on the buccal surface 
the mobility of tooth were within normal limits. The number of teeth in the dental arch was also normal.

Radiographic examination showed unusual root morphology with two separate roots in maxillary left central incisor, with one mesial and the other distal (Fig. 2). The CT examination was carried out and confirmed the presence of two roots in the upper left central incisor and normal roots number in the other teeth (Figs $3 \mathrm{~A}$ and $\mathrm{B}$ ).

Pulp vitality tests and radiographic examination revealed a diagnosis of necrotic pulp with apical periodontitis and root canal treatment was considered as treatment plan.

After placement of a rubber dam, a conventional access opening was made. The mesial canal was immediately located after removing of the roof of the pulp chamber, however, the thin orifice of the distal canal was identified through the extended access toward the distal side by means of an endodontic explorer (DG-16). Both canals were negotiated; working length was estimated using an electronic apex locator Root ZX (J Morita Manufacturing Corporation, Kyoto, Japan) and then confirmed by radiography (Fig. 4). The root canals were prepared using a stepback technique up to a no. $70 \mathrm{~K}$-file (Maillefer, Dentsply, Switzerland), Gates Glidden No. 2, 3 (Maillefer, Dentsply, Switzerland), and copious irrigation with 5.25\% sodium hypochlorite. The root canals were dried with paper points and obturation was performed using lateral compaction technique with AH26 sealer (Dentsply, DeTrey, Germany). Cavit (3MESPE, Seefeld, Germany) was applied as a temporary restoration of the cavity access, and permanent restorations were advised. Figure 5 shows the final X-ray after root canal obturation. After 1 year, the patient has remained asymptomatic, and the follow-up radiograph revealed the healing process of periradicular radiolucency (Fig. 6).

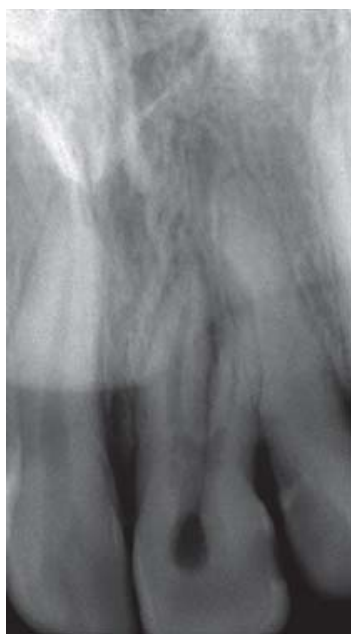

Fig. 2: Preoperative radiograph of maxillary incisors
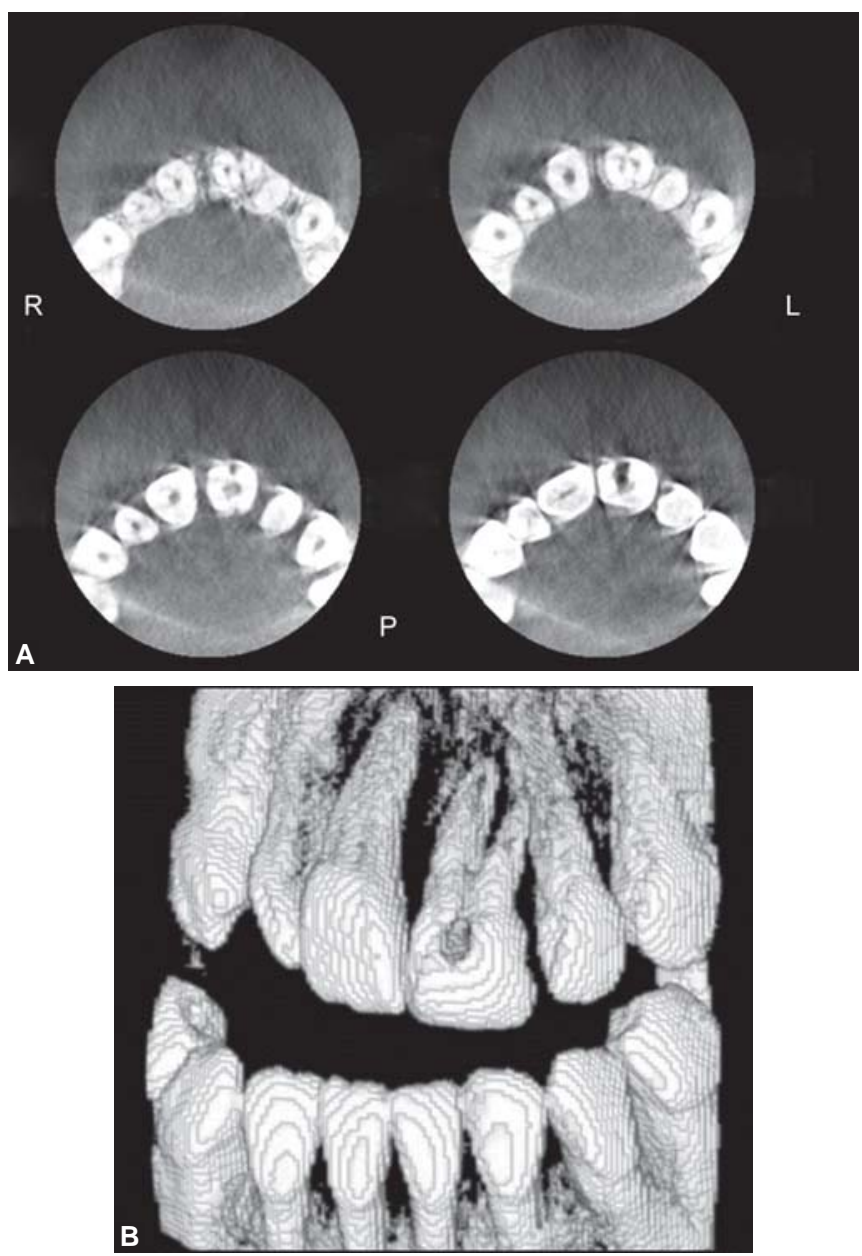

Figs $3 \mathrm{~A}$ and B: CT examination demonstrated two rooted maxillary left central incisor and normal roots number in the other teeth

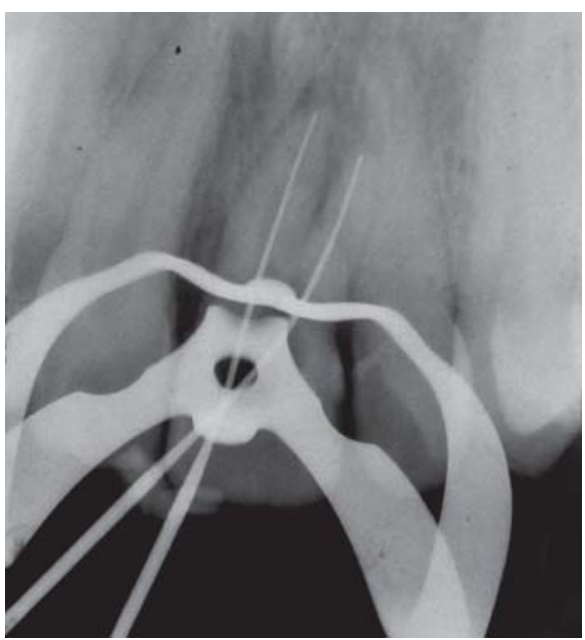

Fig. 4: Working length radiograph for the mesial and distal roots

\section{DISCUSSION}

Although the maxillary incisors are generally considered to have a single root and canal, 2,3 practitioners need to be aware of unexpected anatomical variations when performing root canal therapy. There were few case reports in the literature describing the endodontic management of tworooted maxillary central incisor. ${ }^{4-10}$ 


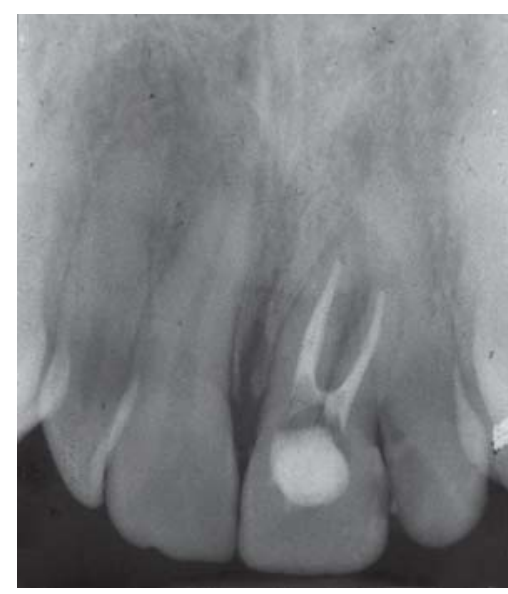

Fig. 5: Postoperative radiograph

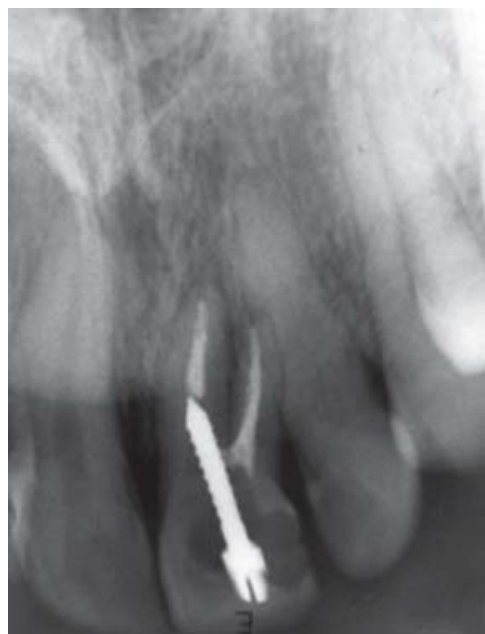

Fig. 6: One-year recall radiograph demonstrated bone healing

Some root canal anomalies are revealed by morphological alteration, such as macrodontia and fusion, ${ }^{11}$ but in the present case the clinical crown was not morphologically different from the upper right central incisor. This points out the importance of a careful preoperative radiographic evaluation, because some teeth may present root anomaly while the clinical crown is normal.

Sabala et a ${ }^{12}$ reported that tooth aberration occurs $90 \%$ bilateral, however Lin et $\mathrm{al}^{9}$ mentioned that two-rooted maxillary central incisors were mostly unilateral. The present case also reports a unilateral maxillary central incisor with two roots. The probable etiology for such unilateral accessory roots may be the traumatic injury of primary teeth. Root duplication may occur following intrusive luxation of primary teeth, resulting in atraumatic division of the cervical loop and formation of two separate roots. In these cases, a mesial and a distal root can be detected on the radiograph. ${ }^{13}$

\section{CONCLUSION}

The case reported here reveals the importance of exact preoperative radiograph, adequate access to and exploration of the tooth's interior, because even the most routine of cases such as maxillary central incisor might deviate from the usual.

\section{REFERENCES}

1. Cleghorn BM, Goodacre CJ, Christie WH. Morphology of teeth and their root canal systems. In: Ingle JI, Bakland LK (Eds). Endodontics (5th ed). Hamilton: BC Decker 2008;1: 151-58.

2. Vertucci FJ. Root canal anatomy of the human permanent teeth. Oral Surg Oral Med Oral Pathol 1984 Nov;58(5):589-99.

3. Sert S, Bayirli GS. Evaluation of the root canal configurations of the mandibular and maxillary permanent teeth by gender in the Turkish population. J Endod 2004 Jun;30(6):391-98.

4. Sinai IH, Lustbader S. A dual-rooted maxillary central incisor. J Endod 1984 Mar;10(3):105-06.

5. Michanowicz AE, Michanowicz JP, Ardila J, Posada A. Apical surgery on a two-rooted maxillary central incisor. J Endod 1990 Sep;16(9):454-55.

6. Lambruschini GM, Camps J. A two-rooted maxillary central incisor with a normal clinical crown. J Endod 1993 Feb;19(2): 95-96.

7. Genovese FR, Marsico EM. Maxillary central incisor with two roots: A case report. J Endod 2003 Mar;29(3):220-21.

8. Gonzalez-Plata RR, Gonzalez-Plata EW. Conventional and surgical treatment of a two-rooted maxillary central incisor. J Endod 2003 Jun;29(6):422-24.

9. Lin WC, Yang SF, Pai SF. Nonsurgical endodontic treatment of a two-rooted maxillary central incisor. J Endod 2006 May;32(5):478-81.

10. Sponchiado EC Jr, Ismail HA, Braga MR, de Carvalho FK, Simões CA. Maxillary central incisor with two root canals: A case report. J Endod 2006 Oct;32(10):1002-04.

11. Cimilli H, Kartal N. Endodontic treatment of unusual central incisors. J Endod 2002 Jun;28(6):480-81.

12. Sabala CL, Benenati FW, Neas BR. Bilateral root or root canal aberrations in a dental school patient population. J Endod 1994 Jan;20(1):38-42.

13. Andreasen JO, Flores MT. Injuries to developing teeth. In: Andreasen JO, Andreasen FM, Andreasen L (Eds). Traumatic injuries to the teeth (4th ed). Blackwell Munksgaard 2007:551.

\section{ABOUT THE AUTHORS}

\section{Amir Maghsoudlou}

Postgraduate Student, Department of Endodontics, Dental Research Center, School of Dentistry, Mashhad University of Medical Sciences Mashhad, Iran

\section{Hamid Jafarzadeh}

Associate Professor, Department of Endodontics, Dental Research Center, School of Dentistry, Mashhad University of Medical Sciences Mashhad, Iran

\section{Maryam Forghani (Corresponding Author)}

Assistant Professor, Department of Endodontics, Dental Material Research Center, School of Dentistry, Mashhad University of Medical Sciences, Mashhad, Iran, Phone: +98 9155143349, Fax: + 985118829500 e-mail: forghaniradm@mums.ac.ir 